\title{
Entrevista com Hermelino Neder
}

\section{ANÁJA SOUZA SANTOS*}

RESUMO: A entrevista que segue foi realizada com o compositor Hermelino Neder, que durante fins de 1970 e meados de 1980 participou da chamada Vanguarda Paulista. O músico em questão integrou nesse período o grupo Hermelino e a Football Music, que gravou somente um álbum, intitulado Como Essa Mulher, pelo selo Lira Paulistana em 1984. Hermelino continuou no campo musical, gravou com Luís Pinheiro o disco Cássia Secreta, pelo selo Espaço Musical no ano de 2010. O compositor escreveu trilhas sonoras para filmes como A Dama do Cine Shangai, Perfume de Gardênia, A Hora Mágica $e$ Onde Andará Dulce Veiga?

PALAVRAS-CHAVE: Hermelino Neder; Vanguarda Paulista; Lira Paulistana.

\section{Interview with Hermelino Neder}

\begin{abstract}
The following interview was accomplished with the musician Hermelino Neder, which during the late 1970s and mid-1980s took part of the so called Vanguarda Paulista (São Paulo's Avant-Garde). In this period this musician integrated the group Hermelino e a Football Music (Hermelino And The Football Music) that recorded only a single album named Como Essa Mulher (Like This Woman) by the label Lira Paulistana (São Paulo's Lira) in 1984. Hermelino remained in musical scene and recorded with Luis Pinheiro the disc Cássia Secreta (Secret Cassia) by the label Espaço Musical (Musical Space) in 2010. The musician also took part of the production of movies soundtracks as A Dama do Cine Shangai (Cine Shangay's Lady), Perfume de Gardênia (Gardenia Perfume), A Hora Mágica (The Magic Hour) and Onde Andará Dulce Veiga? (Where Will Be Dulce Veiga?)

KEYWORDS: Hermelino Neder; Vanguarda Paulista; Lira Paulistana.
\end{abstract}

\footnotetext{
* Anája Souza Santos é Pós graduanda em História pela Universidade Estadual Paulista Júlio de Mesquita Filho, Campus de Franca, com pesquisa na área de Música Popular financiada pela Fundação de Amparo a Pesquisa do Estado de São Paulo (FAPESP). E-mail: anaja.historia@gmail.com
} 
nája Souza Santos: Gostaria que você falasse um pouco sobre a época do teatro
Lira Paulistana, sobre a produção de música independente que ocorreu em São Paulo
em meados da década de 1980 e sobre sua ligação com a chamada Vanguarda Paulista.

Hermelino Neder: Você sabe, a Vanguarda não chegou a fazer um manifesto. Foi uma coisa restrita à cidade. Não teve um manifesto tropicalista antropofágico, então... Nem sei quem inventou esse nome: Vanguarda Paulista. Minha relação com isso tem muito a ver com o Arrigo. Porque quando eu estudava na ECA ${ }^{1}$, vários membros da Vanguarda eram de lá. Vários membros do Premê eram da minha classe: O Claus, Igor Maués, Mário Manga, Marcelo... Do grupo todo, quatro estavam na minha classe. E na minha classe tinha uma menina, chamada Sílvia Ocougne, que foi a capitã da Football Music. Ali na nossa classe, então, já tinha o Premeditando e um "lado B", que era eu e a Sílvia Alcunha. Então a gente se conhecia da ECA. E o Arrigo eu conheci lá [na ECA]. O Arrigo era de uma turma anterior à minha, o Arrigo estudou, se eu não me engano, na turma do Luiz Tatit [...]. Outros integrantes do Rumo, como o Hélio Ziskind, e o Pedro Mourão também estudaram na ECA... Então, minha ligação com esse pessoal era de a gente ser colegas de faculdade.

Santos: A ECA teve um papel fundamental para a formação da Vanguarda Paulista, não é? Ao que parece, tudo começou na ECA.

Neder: É. Agora, o Arrigo tem uma importância mais fundamental no meu trabalho porque a gente tem uma relação bem legal de trabalho entrecruzada. Por exemplo: fui eu que falei pra ele: "Olha, você sabia que vai ter um festival na cultura?". E eu era namorado da Vânia Bastos, na época. Eu que a apresentei a ele. E estávamos - a Vânia e eu - na primeira banda dele, que foi a banda que participou do festival universitário da TV Cultura. Então, você vê que curioso... Eu dei esse toque, eu mesmo não me inscrevi no festival. Eu o tinha visto tocar um dia daquele jeito dele, no piano, e eu tinha achado muito bacana aquela música, aí eu dei esse toque. Eu sei que ele compôs uma música com a Regina Porto que também era da ECA, que é a música

\footnotetext{
${ }^{1}$ Escola de Comunicação e Artes da Universidade de São Paulo.
} 
"Diversões Eletrônicas", que ganhou o primeiro lugar. Acho que o Premê ganhou o segundo.

No disco Suspeito, do Arrigo há algumas composições minhas e dele. Tem "Êxtase”, "Amor Perverso", “Suspeito”, “Uga-Uga”, e “Tchau Trouxa”.

Santos: "Uga-Uga" ficou bem conhecida na época?

Neder: É, ficou um pouco, sim. Eu me lembro do Arrigo na Xuxa, vestido de Troglodita [risos]. Sabe, de Fred Flintstone? [risos]

Esse foi o disco mais popular do Arrigo. E eu acho que o Arrigo me convidou pra trabalhar com ele nesse disco, porque a música de maior sucesso popular do Arrigo é o "Pô Amar é Importante", que não é dele, é minha, né?

Essa música, não sei que lugar da parada atingiu... Tinha uma época na década de 80 que os três mercados fonográficos mais importantes do Brasil (em termos de rádio) eram a grande São Paulo, Grande Rio, outras capitais e Interior de São Paulo. E nesse terceiro, o "Pô! Amar é Importante" tocou muito, tocou muito na capital também. Eu cheguei a ligar o rádio e estar tocando. Uma sensação única que eu tive! [risos] Uma vez eu estava indo para Santos e estava tocando no rádio. O Premê estava no nordeste uma época e eles disseram que minha música tocava tanto que eles ficaram com raiva. Disseram que fizeram até um arranjo pra trio elétrico, carnavalesco, da minha música [risos].

Então, você vê, eu dei esse toque pra ele [Arrigo], de participar do festival, aí ele me convidou pra fazer backing vocal. A Vania também, pra fazer backing vocal... Aí o Arrigo ficou muito famoso, teve uma época que... Nossa! Aí começou esse papo que tinha uma nova música acontecendo em São Paulo e que o Arrigo era um dos líderes. O Itamar nem era conhecido nessa época. Então, a gente nem sabia que o Itamar tinha um trabalho dele. A gente admirava muito o trabalho dele, como ele conseguia tocar aquelas coisas complicadas, dodecafônicas do Arrigo, sem saber ler música, tudo de ouvido, era uma beleza!

Aí quando o Arrigo ficou conhecido teve um projeto, acho que chamava Virada Paulista. E a Regina Person quis fazer um projeto. Ela sacou que estava acontecendo alguma coisa em São Paulo e perguntou pro Arrigo quem ele indicava, 
de músicos novos, que estavam aparecendo. E o Arrigo me indicou. Ele conhecia algumas músicas minhas. E aí com um mês eu fiz todos aqueles arranjos do primeiro disco, depois eu mexi, mas era basicamente aquilo, e nós estreamos com a banda que na época era Santos Football Music. O nome da banda é por causa de uma música do Gilberto Mendes que tem locução de futebol, tem muita coisa de futebol. E eu como sou santista coloquei o nome da minha banda de Santos Football Music. Depois eu mudei, eu saquei que não tinha nada a ver ficar dividindo torcida. Teve um produtor que falou: "Isso não é uma boa ideia, se você quer fazer uma carreira você não vai querer que só os santistas ouçam sua música". O que era uma bobagem, porque se pelo menos a torcida do Santos tivesse seguido minha música teria muito mais gente. [risos] Mas eu duvido que a torcida do Santos teria gostado da minha música.

Santos: Você acredita que o Arrigo Barnabé tenha agido como um elo entre alguns músicos da Vanguarda Paulista?

Neder: É talvez fosse, se bem que o Rumo tinha uma vida própria. Apesar de o Rumo e o Arrigo terem estudado na mesma escola [ECA], eu tenho a impressão que eles tinham uma vida anterior, até. Eles já tocavam, já faziam shows muito cheios.

Depois, muitos anos depois, o Arrigo veio morar comigo, na minha casa. A gente compôs muitas músicas juntos nessa época. E foi na época desse disco mais popular... Eu estava te falando desse disco Suspeito... Acho que foi uma tentativa que o Arrigo fez de tocar no rádio. E aí ele me convidou, eu acho que ele pensava assim: como minha música de sucesso popular é do Hermelino, então, imagino que ele tenha querido trabalhar comigo pra criar outros sucessos. E o "Suspeito" chegou a tocar no rádio, "Uga-Uga" também chegou a tocar.

E esse disco foi meio que um fracasso. Acho que o público do Arrigo sentiu que ele estava meio que traindo, mas não é traindo, né? Não era o Arrigo, né? É muito popular esse disco... Assim, comparado com as coisas dodecafônicas... Mas ele não é tão popular a ponto de tocar no rádio, ele ficou no meio do caminho. Eu temo que o projeto novo do Arrigo com as minhas canções siga esse caminho... Ele acha que é um 
projeto muito popular que vai tocar no rádio... O Arrigo é tão bom, tão criativo... Os arranjos tão ficando lindos assim, com muito bom gosto².

Santos: Me parece que vocês, músicos ligados a Vanguarda Paulista, eram muito uma turma de amigos, não é?

Neder: A gente era, a gente era sim. O Mário Manga chegou a tocar violoncelo na minha banda um tempo, eu tentei fazer uma composição com ele. $\mathrm{O}$ Itamar, uma vez eu quis inscrever uma música num festival, não sei se era da Globo... E o Itamar gravou cantando pra mim, porque eu gostava muito do jeito que ele cantava. Então a gente tinha ligação mesmo. Só recentemente que eu comecei uma relação com o Luiz Tatit, porque o Tatit estava na minha banca de doutorado. E aí eu fiz uma música usando a técnica de composição que eu desenvolvi nessa tese. Então ele conhecia minha técnica pela banca. Então depois que ele já conhecia, ele gostou e tudo. Então eu fiz uma música e falei: “Ô, Tatit, você não quer pôr letra?” Aí ele fez a letra. Essa música chama "Impassível”. É minha única parceria com o Tatit, está no disco que o Arrigo e o Tatit estão lançando agora.

Santos: Seu trabalho está muito interligado ao do Arrigo, não é?

Neder: Sim, está muito interligado. Existe outra passagem que foi muito importante pra mim, principalmente: a gente morava junto e fez uma música que veio a se chamar depois "Sky Of My Blues”, que ganhou esse nome quando o Carlos Rennó botou uma letra em inglês. É uma bossa nova. Antes de ganhar essa letra, ela foi o tema do filme A Dama do Cine Shangai. Eu ganhei um monte de prêmios com essa trilha. E a música do Arrigo está lá. E eu estava inseguro, né? E a gente morava junto e eu falei: “Ô Arrigo, tem um cara aí me sondando pra fazer a trilha de um filme”. Ele falou assim pra mim: “Os diretores de cinema são muito inseguros, então se você chegar pra ele e falar assim: 'Cara, ninguém vai fazer essa música melhor do que eu', ele vai acreditar" [risos] O Arrigo falou assim: "Fala isso, grava 'Sky Of My Blues', e dá pra ele escutar". Então eu gravei. Eu tocando violão e o Mané Silveira tocando saxofone. O cara queria

\footnotetext{
${ }^{2}$ Hermelino se refere ao projeto de Arrigo, levado a cabo em 2014, em que este interpreta as canções do disco Como Essa Mulher.
} 
um tema de sax, tinha que de ter "um tema de sax". Então o cara escutou e adorou. E essa música é muito bonita, mesmo, dessa eu gosto muito mesmo. Não é a única música do filme. O resto da trilha eu fiz usando minha técnica de composição.

Santos: Você utilizou essa técnica de composição nas canções do disco Como essa Mulher: Pô! Amar é Importante?

Neder: Não tinha feito ainda a técnica não tinha sido criada. Já estava desenvolvendo, porque eu comecei a pensar nela na época em que eu era estudante da ECA, mas eu só vim desenvolver mesmo depois, principalmente fazendo trilha sonora pra cinema.

Na década de 1980 eu estava achando um jeito de organizar, um jeito de usar as doze notas pra criar minha música [...]. Eu fiz minha tese de doutorado usando essa técnica. O nome da técnica é Campos Harmônicos Seriais. O nome da minha tese é "Música pura com os Campos Harmônicos Seriais" 3 .

Santos: Eu gostaria que você falasse um pouco sobre o processo de produção independente. Você considera que ser independente acabou sendo uma escolha dos músicos ligados à Vanguarda Paulista?

Neder: Eu tenho a impressão de que ninguém queria ser independente. Mas como era difícil conseguir um contrato numa gravadora com esse tipo de música...

Nessa época, a gente pedia dinheiro emprestado e conseguia pagar o estúdio, o artista da capa, a prensagem do disco, entendeu? O meu disco só tem 1000 cópias, é raríssimo. Mas "independente" eu imagino que queira dizer independente das gravadoras: eu pago meu disco. Aí, o Lira Paulistana, que tinha o teatro Lira Paulistana e depois virou uma gravadora também, o que eles fizeram foi me ceder, me emprestar o selo.

Santos: Sobre seu disco: Como essa mulher!, eu gostaria que você comentasse sobre a proposta estética contida nele.

\footnotetext{
${ }^{3}$ A tese se encontra disponível na PUC- São Paulo.
} 
Neder: Tinha um compositor de Vanguarda, chamado Luciano Berio, italiano, que fez uma série de composições chamada Folk Songs. Ele pegou canções folclóricas de vários lugares do mundo e fez arranjos com instrumentos eruditos e usando técnicas de composição de vanguarda. Ele tem uma música que é pra viola; viola clássica e voz. No meu disco tem uma música pra violino, voz e violão, mas tem um momento em que só o violino toca com a voz. Eu fiquei muito encantado com esse disco, com a possibilidade de misturar música popular com música erudita de vanguarda. Essa é a proposta do primeiro disco da Football Music. Então, na banda tinha: baixo, bateria, guitarra ou violão, teclado ou piano e backing vocal. Esses elementos são todos da área da música popular. Tinha também violino, clarineta ou flauta, que são instrumentos de orquestra. Tinha uma época em que teve clarone. Em outra época teve trombone, outra época teve violoncelo, que são instrumentos da música erudita. E uma das faixas do disco, faixa que se chama Santos Music Club, é uma peça instrumental erudita de vanguarda, daquelas chatas de escutar, complicada [...]. Então, a proposta do disco era misturar mesmo música erudita com música popular. Então, no disco tem samba, tem bossa nova, tem uma música brega - que é o "Pô! Amar é importante" -, tem rock, tem blues. Então, a ideia do disco é parecida com a ideia do Luciano Berio, das Folk Songs.

Santos: Você tinha como objetivo ser reconhecido como compositor de música popular?

Neder: Não, eu não tinha esse negócio, não. Eu achava chique fazer uma música diferenciada. Eu tinha certa vaidade em não fazer uma música estritamente popular. Quando as pessoas perguntavam: que tipo de música você faz? Eu falava assim: "Eu faço uma mistura de música popular com música erudita". Que é verdade. Mas, aliás, o Arrigo também, o Tatit também, o Premê também.

O Premê parece um grupo de vanguarda italiano chamado I Musici ("os músicos" em italiano), que era um grupo de música erudita muito engraçado. Eles quebravam com a tradição, o lance da vanguarda é quebrar com a tradição, né? Cada um dos compositores quebrou de um jeito. O I Musici quebrava pela coisa teatral, de 
brincar com os rituais da música erudita [...], então eles brincavam com isso. O Premê parecia muito com o I Musici.

No Arrigo essa mistura de erudito e popular está na própria composição. No meu caso está nos arranjos, como no caso do Luciano Berio ${ }^{4}$. No caso do Arrigo não, a própria música já era de vanguarda, por que ele usava uma técnica de vanguarda. Enquanto eu não fiz o meu sistema de composição, a minha composição era tonal, as minhas músicas todas do primeiro disco eram tonais, acho que menos uma que é modal e essa outra que chama "Santos Music Club", que é atonal.

O Tatit, o jeito que ele cantava, meio falado, parece com uma coisa que o Schoenberg inventou que chama em alemão Sprechgesang. Sprech é de fala e Gesang é de canto, então, canto falado. Ele tem uma obra linda, difícil de escutar também, que se chama Pierrot Lunaire, onde a cantora canta falando, muito parecido com o canto falado do Rumo. Na verdade, o Tatit chegou à conclusão que o canto é uma extensão da fala que ele chama de entoação.

Santos: Alguns músicos que como você, fizeram parte da Vanguarda Paulista, assumem certo legado da Tropicália. Eu gostaria de saber se você sente essa influência na sua obra.

Neder: Super! Influência direta, não é uma influência consciente, mas é evidente, porque eles foram os primeiros que misturaram, né? A gente também misturou. A gente é quase uma consequência disso, eles já usavam coisas eruditas, porque o Rogério Duprat e outros arranjadores que trabalhavam com eles já eram da área erudita, então de certa maneira a Vanguarda Paulista é uma consequência do Tropicalismo e um aprofundamento, uma radicalização do tropicalismo. Porque o Tropicalismo mistura tudo, mistura os gêneros... Então esse é um lado da questão, não sei se não tivesse tido a Tropicália se a gente faria como a gente fez, ou então nós seríamos a tropicália... Engraçado eu falar "nós" porque eu não me sinto fazendo parte dessa...

\footnotetext{
${ }^{4}$ Embora Neder relacione Luciano Berio à atividade de elaborar arranjos, como fez em Folk Songs, convém lembrar que o músico italiano possui uma ampla produção que não se resume à atividade como arranjador. Pelo contrário, Berio se notabilizou muito mais como compositor do que como arranjador.
} 
É claro que eu tenho, que eu sou do "lado B" da vanguarda [risos], mas eu não me assumo muito por algum motivo.... No meu caso tem uma outra coisa que é o seguinte: eu gosto muito do Caetano como personalidade e do Gil como compositor. Então, eu tenho a impressão que o Caetano foi o artista que mais me influenciou como comportamento: de liberdade, as coisas que ele falava sobre política... Na nossa época, a gente ficava esperando o próximo disco do Caetano... Imagina a força disso, né? O seu ídolo! O meu ídolo é o Caetano, no Brasil, e fora do Brasil o John Lennon. Isso entre os populares, entre os eruditos são outros. Então, claro que tem influência fortíssima, mais forte do que qualquer outra coisa, né? Mas no meu caso tem muita influência do iê-iê-iê também. Se bem que isso já estava dentro da Tropicália também.

Santos: Uma das características da Tropicália é sua relação com os meios de comunicação de massas. O Caetano, por exemplo, nunca negou seu desejo de comunicar-se através da televisão. Você pode me falar um pouco sobre como se dava a relação dos músicos da Vanguarda Paulista com os meios de comunicação de massas? Se comunicar com o público através deles também era um desejo de vocês?

Neder: A gente queria, mas a gente não conseguiu [risos]. Você viu a tentativa do Arrigo com esse disco, o Suspeito? Esse disco é uma tentativa, e agora ele está fazendo de novo, e de novo comigo [risos]. Tentativa de fazer uma coisa popular, uma coisa que dê dinheiro, entendeu? Porque senão virá só projeto cultural, pra pouca gente, né? Mas aí o Arrigo pega uma música minha, um samba meu, por exemplo, em 2 por 4, que é o compasso tradicional do samba, e faz em 5 por 4 [risos]. Quer dizer, ele quer fazer popular, ele pega uma música popular e faz um arranjo lindo! Chamase "Sandra", essa música. É uma coisa linda, o arranjo que ele faz, mas será que é lindo pra todo mundo ou será que é lindo pra mim que tenho um ouvido treinado? As pessoas que são o público do Arrigo, que vão escutar o Arrigo, acham aquilo lindo, mas será que aquilo vai tocar no rádio? O Arrigo acha que vai, ele continua sonhando... Então, mas é diferente da Tropicália, porque a gente gostaria... Por quê? Porque sim, quem é que não quer ser conhecido pelo seu país, tocar no rádio, ganhar dinheiro, ser famoso, não é? Todo mundo quer. É claro que a gente gostaria de ter feito o sucesso que o Caetano fez e tal, mas a gente não tinha a proposta declarada, visceral, dentro 
do movimento de falar assim: "Eu quero me comunicar com os meios de comunicação de massa, então eu vou fazer uma música assim, assim, assim”. Por exemplo, eu vou colocar guitarra elétrica no samba porque o público jovem gosta de guitarra elétrica... Nós não tínhamos isso. Pelo contrário, eu queria fazer uma coisa que quebrasse... Claro que eu queria também que fizesse sucesso. É muita pretensão, né? [risos] Isso é a cabeça da gente que estudava lá na ECA. Tinha uma pregação mesmo, dos professores, pela música de vanguarda, pela música que a burguesia não conseguisse entender, uma conversa assim...

O Itamar parece que era o cara que gostava mais de levantar uma bandeira dizendo: "Eu não me vendo à indústria cultural". Ele era do tipo assim: "Não quero que ninguém dê palpite na minha música, que faço do jeito que eu quero!" Uma vez eu fui convidado pra escrever um texto sobre um disco que ele estava lançando. Aí eu escrevi um texto onde mostrava a criatividade, a originalidade, de certa maneira eu mostrava como era um disco fino. Ele ficou meio irritado [risos]. Ele falou: "Pô a gente tenta fazer uma coisa popular, mas não adianta a gente não consegue!"

Santos: Eu gostaria que você falasse sobre o título do seu disco, me parece que há algo de ambíguo. Esse duplo sentido seria intencional?

Neder: Sim, o disco é muito apaixonado, tem canções de amor...

Santos: Inclusive a canção que você chama de brega, não é? "Pô, amar é importante!"

Neder: Nossa senhora! "Você imagina a aflição que eu fico?" [risos] E "Como essa mulher" (nome da canção) tem isso também: "Como essa mulher maltrata minha cabeça!".

Santos: Mas a palavra como está mesmo se referindo ao ato sexual, não é?

Neder: É! Você se lembra da letra? “Ela vem no meu quarto, deixa um cheiro forte no lençol, toca mi natural onde é bemol” Não é? “Ela tem um namorado, ela tem um papo incerto, que diz que o incerto é muito mais in que o certo"-. É uma menina de vanguarda que está descrita nessa letra. Ela na casa do cara, mas ela tem um namorado. 
Ou seja, o cara que fez a música está comendo ela, não é? Ele não namora ela, ele come ela, mas é apaixonado por ela. Mas ele não é namorado dela. Não é "eu caso com essa mulher", ou "eu namoro com essa mulher", ele come ela [...]. Ele até gostaria de ser namorado dela, mas não é, porque ela já tem um namorado [risos.]

\section{Santos: Há muita irreverência no disco?}

Neder: Totalmente. Aliás, o Augusto de Campos escreveu uma carta de recomendação. Nessa carta, ele fala que havia alguns grupos, algumas músicas daquela época que eram bem humoradas. Tinha o Língua de Trapo - que era considerado também da Vanguarda Paulista, e que eu não entendo por que, mas é considerado -, tinha o Premê que tinha humor, mas humor meio de vanguarda, parecido com o I Musici Então, o Augusto de Campus naquela carta de recomendação, ele escreve assim, entre outras coisas: “O humor do trabalho do Hermelino não está só na letra, que é o caso do Língua de Trapo e que veio a ser depois o caso dos Mamonas: eles faziam uma música normalzinha, a letra que era engraçada”. O que ele [Augusto de Campus] percebe é que o humor entra nos arranjos. Isso é verdade, você ouve os arranjos e percebe uns barulhos, umas coisas, meio que comentando a letra...

Santos: Porque você não considera que o grupo Língua de Trapo tenha sido parte da Vanguarda Paulista?

Neder: Porque não tinha nada de erudito... Era humor e popular. Aí você poderia me questionar: "E o que tem de erudito no Itamar?" O Itamar faz um reggae, faz uma música popular de muita qualidade. Acho que não tem essa qualidade na música do Língua de Trapo. Era muito engraçado, os shows eram muito engraçados. Não sei, mas se você nota, você pode fazer uma relação do Premê com o I Musici Você pode fazer uma relação diretíssima, do Arrigo com a vanguarda do dodecafonismo. $\mathrm{O}$ próprio Luiz Tatit, embora querendo fazer uma música popular, baseada na entoação, faz uma música que parece o canto falado do Schoenberg. A minha música tem a influência do Luciano Berio. Mas alguns outros, a Eliete Negreiros, quando chama o Arrigo pra produzir o disco dela, traz toda a estética erudita dos arranjos na composição que ela canta. Agora, o Itamar e o Passoca, que fazem uma música de 
muita qualidade, eles não têm um viés (eu não gosto muito dessa palavra, "viés", mas não sei que outra palavra usar) erudito, como também não tem na música do Língua de Trapo. Agora, o Passoca e o Itamar, o que eles têm aqui e que tem muito a ver com os outros trabalhos de Vanguarda Paulista, é a qualidade. É muita qualidade, né? É muito refinado. Eu vejo o Língua de Trapo como uma coisa escrachada, embora eles tocassem bem e era muito engraçado, era muito bem feito do ponto de vista teatral e cômico.

Santos: E em relação ao público, você fez o disco pensando em um público específico?

Neder: $\mathrm{Eu}$, na verdade, era mais bobo, mais ingênuo... Eu estava mais preocupado em agradar os intelectuais, os meus pares, fazer uma coisa diferenciada... Eu tinha uma vaidade, né? De fazer uma música diferente, original, que tivesse um status parecido com a música do Arrigo. Eu tinha inveja do Arrigo nesse sentido: "Pô, ele faz uma coisa tão diferente e consegue ser tão famoso, aparecer tanto!" Então eu queria alcançar esse tipo de sucesso. Não é o sucesso do Roberto Carlos, é um sucesso mais parecido com o do Arrigo e do Caetano. Se bem que o do Caetano tinha uma coisa mais popular.

Santos: O Caetano e o Gil, e outros compositores da chamada MPB, possuíam na década de 1960, certo status de intelectuais. Você buscava esse tipo de reconhecimento?

Neder: Eu queria fazer uma música assim. Agora, eu nunca gostei de música chata...

Santos: Chata, em que sentido?

Neder: Música erudita de vanguarda chata... Tem muita música erudita muito difícil de escutar. O sistema tonal é um sistema que tem a ver com a maneira que o ser humano ouve música porque o sistema tonal tem um centro, então as coisas se organizam em torno desse centro. Você sabe quando a música acaba, você sai do centro e volta para o centro. Então é uma coisa - sei lá se a palavra está certa - bastante natural. O próprio som é a resultante de outros sons que são chamados sons 
harmônicos. Então, assim: tem uma série harmônica, né? Então, na própria ideia de som tem a ideia de um som fundamental. A música tonal também tem, tem um centro que organiza as outras coisas que acontecem. Então em todo o mundo tem... Na música modal também tem um centro. Então essa coisa de ter um centro parece que é um jeito meio natural humano de ouvir, de organizar a música. As músicas de vanguarda quebravam o centro, a ideia do dodecafonismo, de nenhuma nota ter mais poder que a outra, ter mais peso do que outra, é uma ideia antinatural de certa maneira. Então, torna isso uma música difícil de ouvir, desconfortável. Algumas são muito chatas. Para mim, tem muita música erudita insuportável dessa época. Eu não aguento escutar. Músicas muito inteligentes, mas que precisavam de explicação pra ouvir, precisava ter bula pra poder ouvir, isso eu nunca engoli. Então, eu gostava de brega, gostava de Roberto Carlos, de Adoniram Barbosa, de "Aquele Abraço" do Gil... São músicas muito bonitas! Então, eu nunca quis fazer uma música chata. Eu gostava de algumas conquistas da vanguarda, queria fazer uma música diferente, tinha a vaidade de fazer uma música diferente. Queria ter um tipo de sucesso inteligente, mas eu nunca consegui fazer uma música que, no meu disco tem duas músicas bem chatas que escaparam [risos]!

Santos: Quais são as canções que você considera chatas?

Neder: "Santos Music Club" e "Blues". São duas músicas que assim... É impossível você estar naquele meio e não dar uma derrapada, né? [risos] "Santos Music Club" é uma música de vanguarda que eu gosto. Agora, o "Blues" é realmente esquisito, mesmo. É cerebral demais, perde um pouco a naturalidade.

Santos: O que você pensa sobre a formação da banda do Arrigo, que está fazendo um show com suas composições, atualmente?

Neder: Ele faz um resumo da minha banda. Porque ele tem baixo, guitarra, bateria e clarineta. E ele tem as cantoras que fazem backing vocal e em algumas músicas, as cantoras cantam. Os solos também, embora seja um show de um artista que é o Arrigo, acompanhado por elas, eles distribuem um pouco os solos também. Parece um pouco com o jeito que era a Football Music. 
Santos: Você sabe por que a banda é formada apenas por mulheres?

Neder: Tenho uma canção chamada "Luana", que não está no meu disco. Eu não lembrava, o Arrigo que lembra que ela não está no disco porque foi censurada, em função de os censores acharem a letra meio pornô. A censura que achava, mas eu não lembro, quem lembra é o Arrigo. Mas essa música, uma vez eu abri o show do Arrigo com ela. Eu cantei tocando violão junto com a Silvia Ocougne ${ }^{5}$. Então, nós tocamos e o Arrigo gostava muito dessa música. E durante muitos anos ele pensava em cantar essa música no show dele. E aí, uma época, o Arrigo sugeriu que o irmão dele, Paulo Barnabé, fizesse um show com as minhas músicas, mas o Paulo não gostou da ideia e aí o Arrigo se tocou que ele mesmo queria fazer. Ele achava esse projeto legal, aí ele quis fazer. Ele estava fazendo um show de muito sucesso com as músicas do Lupicínio Rodrigues, que se chama Caixa de Ódio, no qual ele desenvolveu o lado ator dele, porque as músicas do Lupicínio permitem muito que você seja ator. E o Arrigo é muito ator no palco. E aí, quando ele quis fazer um novo show pra explorar esse lado [ator], ele achou que as minhas canções também tinham isso. Então, ele falou: "Eu vou fazer um show com as músicas do Hermelino". O que ele pensou a princípio? Ele queria fazer uma banda com meninos, homens... Ele chegou até a convidar um músico pra ir à casa dele um dia e o cara falhou, por algum motivo não foi. Nesse dia em que o cara não foi, parece que ele recebeu um e-mail de uma menina que já tinha tocado com ele. Não sei bem como foi, mas teve uma coincidência... Ele falou: "Porque eu não faço uma banda de meninas?". Ele sacou! Porque tem tudo a ver: é muito engraçado por que tem muitas músicas que tem palavrão e é muito legal as meninas cantando. Não ser só coisa de machista, as meninas assumirem o discurso junto, fica muito bom. Acabou sendo um achado e tem também de certa maneira uma ligação com a história, porque o Itamar teve numa época, uma banda só de meninas, chamavase As Orquídeas. Então o Arrigo de certa maneira recupera um pouco essa história.

\footnotetext{
${ }^{5}$ Integrante do grupo Football Music.
} 
Santos: É possível notar nas obras de outros compositores da Vanguarda Paulista uma níti. "Pô, amar é importante!" da referência à cidade de São Paulo. É possível afirmar que essa referência existe também nas suas canções?

Neder: Olha a capa do meu disco: o muro, a pichação, são coisas de São Paulo. Não é consciente, nunca pensei em São Paulo como tema. Na canção “Como essa mulher", a moça descrita é paulistana, em Ourinhos não tinha ninguém desse jeitotambém é mais urbana, tem a ver com Woody Allen...

Minhas músicas não se referem a São Paulo como no Arrigo ou no Premê. Tem uma música, chamada "Minha Melhor Amiga" que a Cássia Eller quis gravar. Nessa tem uma coisa bem paulistana, mas ela é posterior à Vanguarda Paulista.

Os dois primeiros discos dela (da Cássia) foram de músicas dos “vanguarderos" aqui de São Paulo. Não fizeram sucesso. Ela foi fazer sucesso quando ela se associou aos cariocas e ao Nando Reis, que é de São Paulo. Então, essa música "Minha Melhor Amiga", é minha música mais paulistana. 